\title{
Creencias y valores religiosos en los criterios de auto-gobierno de jóvenes políticos en México ${ }^{1}$
}

Religious beliefs and values in the criteria of self-government of Young politicians in Mexico

Crenças e valores religiosos nos critérios de autogoverno de jovens políticos no México

Edgar Zavala-Pelayo ezavalp@ $@_{\text {zedat.fu-berlin.de }}$ Recibido: 6 de junio 2016 Aprobado: 3 de octubre 2016

\section{Resumen:}

En este artículo se presenta evidencia empírica sobre los valores y creencias religiosas de un grupo de treinta y dos jóvenes dirigentes políticos, afiliados a partidos de derecha, centro e izquierda en México. El propósito del artículo no es ofrecer un estudio meramente descriptivo de perfiles religiosos individuales sino un primer análisis micro-meso que sugiere la posibilidad de encontrar vínculos entre las creencias y valores religiosos de un grupo de políticos jóvenes en un contexto latinoamericano y lógicas de gobierno pastoralistas de acuerdo a la tesis foucaultiana de la gubernamentalidad moderna.

Palabras clave: América Latina, gubernamentalidad, pastoralismo, religión y política, valores religiosos.

1 Esta es una versión revisada del texto presentado en el grupo de trabajo de Sociología de la Religión, durante el XXX Congreso de la Asociación Latinoamericana de Sociología, San José, Costa Rica. Agradezco a los miembros de este grupo de trabajo por sus preguntas y comentarios sobre el texto original. 


\section{SIWÔ ’ Volumen 9, Números 1, 2015}

\begin{abstract}
:
The article presents empirical evidence about the religious beliefs and values of thirty two young politicians from rightist, centrist and leftist political parties in Mexico. The article's aim is not to offer a descriptive account of individual religious profiles but to present an introductory micromeso analysis that suggests the possibility of finding links between the religious beliefs and values of young politicians in a Latin American context and Foucault's thesis of Christian pastoralism as one of the elements of modern governmentality.
\end{abstract}

Keywords: Latin America, governmentality, pastoralism, religion and politics, religious values.

\section{Resumo:}

Neste artigo apresenta-se evidência empírica sobre os valores e crenças religiosas de um grupo de trinta e dois jovens dirigentes políticos, afiliados a partidos de direita, centro e esquerda no México. $\mathrm{O}$ propósito do artigo não é oferecer um estudo meramente descritivo de perfis religiosos individuais, mas sim uma primeira análise micro-meso que sugere a possibilidade de encontrar vínculos entre as crenças e valores religiosos de um grupo de políticos jovens em um contexto latino-americano e lógicas de governo pastoralistas de acordo à tese foucaultiana da governabilidade moderna.

Palavras clave: América Latina, governabilidade, pastoralismo, religião e política, valores religiosos.

\section{Introducción}

Los estudios sobre religión y política en América Latina son ampliamente diversos en sentido teórico, temático y metodológico. De forma muy preliminar estos trabajos pueden dividirse en tres apartados generales inter-dependientes. Primero, los trabajos enfocados en los vínculos entre los elementos y formas institucionales de lo religioso y lo político -por ejemplo, los numerosos trabajos sobre iglesias (católicas y cristianas), y estado (Blancarte 1992; Contreras 2012; Freston 1999; Mancilla 2011; Maroto 2014; Masferrer 2013; Parker 2012; Restrepo 2006; por mencionar solo unos cuantos); o religiones y partidos políticos confesionales y seculares (Bastian 1999; Duque 2010; Franco 2009; Freston 2008; Prieto 2014; Zub 2008). Segundo, los 
trabajos que analizan elementos institucionales de lo religioso y lo político pero que enfatizan sobre todo las relaciones religiónpolítica en eventos específicos, por ejemplo el rol de la teología de la liberación en la revolución sandinista en Nicaragua (Casanova 2001; Löwy 1996, Reed 2008), o el papel de la Iglesia católica en las dictaduras del siglo XX en Sudamérica (Bustamante 2009; Strassner 2006; Vieira 2009), o el levantamiento zapatista en el Sur de México (Marroquin 1996). Tercero, los trabajos primariamente enfocados en los efectos éticos y sociopolíticos que los vínculos religión-política generan, por ejemplo, los valiosos estudios sobre religiones y derechos humanos, sexuales y reproductivos (Blancarte 2014; Lamas 2008; Moran 2013; Ruibal 2014), o religiones y sus efectos en participación política (Steigenga 2001, Vazquez 2008, Fediakova/Parker 2006).

La diversidad temática de estos trabajos viene acompañada de posicionamientos teóricos y metodológicos variados que, no obstante, tienden a compartir tanto una visión crítica de la secularidad como la desaparición y privatización (Casanova 2006) de lo religioso como un interés implícito o explicito por contribuir directa o indirectamente a la laicidad de las sociedades contemporáneas o a su efectiva emancipación (cf. Casanova 2011) de las dimensiones religiosas.

Los avances de investigación que se presentan brevemente en este texto forman parte de un proyecto que ha sido enriquecido por el valioso material empírico de los estudios anteriores. Sin embargo, las bases teóricas y metodológicas de este proyecto descansan mayormente en una literatura que aborda lo político y lo religioso desde otros ángulos epistemológicos. Estos estudios, aunque diversos disciplinaria y teóricamente, suelen converger en una actitud cautelosa y escéptica no tanto hacia la desaparición y privatización de lo religioso sino hacia la esperada emancipación de las sociedades contemporáneas de las dimensiones 


\section{SIWÔ' ${ }_{\text {volumen } 9, \text { Nimerers } 1,2015}$}

religiosas. En este sentido puede leerse la tesis de Schmitt (1985) sobre los conceptos de la teoría moderna del estado como conceptos teológicos secularizados; las posibles convergencias de las dimensiones teológica y política que Lefort (2006) sugiere; o la genealogía teológica cristiana del estado moderno y el consenso democrático que Agamben (2011), basado en Schmitt entre otros, propone. La obra de Foucault sobre el pastoralismo $(2003: 25-6,31-2 ; 1983 ; 2007 ; 2011 ; 2014)$ como uno de los ingredientes genealógicos de la gubernamentalidad en sociedades modernas puede también sumarse a este grupo de autores. Teniendo como marco de referencia el catolicismo en Europa, Foucault propone que las técnicas y lógicas para gobernar almas, en lo individual y en comunidad, que la Iglesia católica forjó y aplicó a partir de la institucionalización del catolicismo como religión oficial del imperio romano - desde la concepción de un control asimétrico, íntimo y de orientación salvífica sobre el individuo y la totalidad (Foucault 1983, 2007, 2011), hasta la auto-vigilancia y obediencia permanente por parte del individuo (Foucault 2014) - constituyen elementos que, con menores o mayores desplazamientos y modificaciones, contribuyeron fundamentalmente al desarrollo de la gubernamentalidad moderna o el arte "secular" de (concebir y) gobernar poblaciones por parte del estado. Es esta propuesta teórica-conceptual en la cual se basa la investigación cuyos resultados iniciales se presentan aquí.

Dicho proyecto de investigación se propone verificar la presencia y operación de técnicas y lógicas pastoralistas más allá de Europa, en el contexto latinoamericano. Una parte de este proyecto es el análisis genealógico (Foucault 1977) de metodologías "pastoralistas" como parte del régimen colonial de gobierno en la Nueva España (Zavala-Pelayo 2014: 96-100; 2016). Otra parte fundamental del proyecto es el análisis de las rupturas y continuidades entre metodologías coloniales pastoralistas y la racionalidad política de un grupo de jóvenes políticos 
en México. Como parte de este análisis de casos específicos, se presentará a continuación evidencia sobre las creencias y valores religiosos que los jóvenes políticos mencionados reportaron en una serie de entrevistas semiestructuradas. Con el fin de ir más allá del dato agregado (Pew Research Center 2015) y un contexto meramente individual y sincrónico, esta creencias y valores se presentarán, muy concisamente, en términos de 1) sus rupturas y continuidades con el entorno familiar de los entrevistados y 2) sus diferencias y similitudes respecto a las creencias de otros grupos de jóvenes políticos que los mismos entrevistados reportaron. Este abordaje micro-meso se ofrece como un acercamiento inicial para introducir los criterios de auto-vigilancia, o "micro-regímenes" (Bröckling, Krasmann, Lemke 2011: 16) de auto-gobierno moral de este grupo de políticos y, de esta forma, poder estudiar en futuros análisis, las posibles contribuciones de metodologías pastoralistas de gobierno en la "racionalidad política" (Foucault 2011) de los entrevistados.

\section{Notas metodológicas}

La determinación del número de entrevistados obedeció a criterios de factibilidad operativa y de muestreo "ilustrativo" (Mason 2002). El número factible y suficientemente ilustrativo de entrevistados se estimó entre 18 y 30, es decir, entre 6 y 10 dirigentes jóvenes ${ }^{2}$ por cada uno de los tres partidos políticos considerados: Partido Revolucionario Institucional (PRI), Partido Acción Nacional (PAN); Partido de la Revolución Democrática $^{3}$ (PRD). Aunque estos partidos no representan todos los

2 La edad muestra se fijó entre 20 y 30 años. Únicamente dos dirigentes hombres rebasaron este límite ( 31 y 35 años).

3 De forma genérica el PRI puede clasificarse como partido de centro, centro-derecha o, según algunos entrevistados, como "centro-izquierda"; el PAN sería partido de derecha, o centro-derecha; el PRD sería partido de izquierda o en ocasiones de 
partidos políticos actualmente activos en México, sí representan los partidos más votados por la población en elecciones locales, estatales y federales en las últimas décadas ${ }^{4}$.

Para efectos de comparación, se seleccionaron adicionalmente dos regiones consideradas opuestas en términos socio-culturales: 1) la Zona Metropolitana del Valle de México, ("ZMVM" en adelante; incluye Ciudad de México y zonas conurbadas del Estado de México), una región considerada mayormente liberal y políticamente de centro o izquierda; y 2) la región CentroOccidente, considerada conservadora y de mayorías políticas de centro o derecha ("Centro-O."; incluye estados como Jalisco, Aguascalientes, Guanajuato, Michoacán). El número final de jóvenes dirigentes entrevistados ${ }^{5}$ ascendió a 32.

\begin{tabular}{|c|c|c|c|c|}
\hline Partido -orientación* & Región & Mujeres & Hombres & $\begin{array}{c}\text { Total por } \\
\text { partido }\end{array}$ \\
\hline \multirow{2}{*}{ PRI -centro } & Centro-O. & 2 & 4 & \multirow{2}{*}{10} \\
\hline & ZMVM & 1 & 3 & \\
\hline \multirow{2}{*}{ PRD -izquierda } & Centro-O. & 0 & 4 & \multirow{2}{*}{10} \\
\hline & ZMVM & 2 & 4 & \\
\hline \multirow{2}{*}{ PAN -derecha } & Centro-O. & 1 & 4 & \multirow{2}{*}{12} \\
\hline & ZMVM & 2 & 5 & \\
\hline \multicolumn{2}{|c|}{ Total por género } & 8 & 24 & 32 \\
\hline
\end{tabular}

*La orientación política de los partidos se ha simplificado para efectos expositivos; ver nota 2.

centro-izquierda. Estas categorías relativas se utilizan únicamente como descriptores expositivos no absolutos.

4 De acuerdo a estadísticas relativamente recientes, en el año 2012 el 63\% del total de municipios en México estaba gobernado por el PRI, el $16 \%$ por el PAN y el $10 \%$ por el PRD (Federación Nacional de Municipios... s.f.).

5 Tres entrevistas piloto fueron realizadas antes de comenzar las entrevistas definitivas. Una de las entrevistas, al momento de llevarse a cabo, se convirtió en un grupo focal no planeado de 3 participantes. A excepción de una entrevista realizada por videollamada, todas las entrevistas fueron presenciales. 
Dada la naturaleza específica de los sujetos de estudio ${ }^{6}$, el método para reclutar entrevistados fue no probabilístico e involucró una selección directa y, una vez entrevistados los primeros dirigentes, un muestreo de "bola de nieve" (Blaikie 2000: 205; Seidman 2006: 55). La cantidad proporcionalmente menor de mujeres jóvenes dirigentes en los partidos seleccionados impidió entrevistar un número similar de hombres y mujeres. Las entrevistas se realizaron bajo un formato semi-estructurado que incluyó, entre otras, preguntas sobre la trayectoria política del(la) entrevistado(a), su opinión acerca de la religión y la política en México y sobre sus creencias, valores y afiliaciones religiosas.

La lógica en la secuencia de preguntas era sondear temas cada vez más complejos y personales a medida que la entrevista avanzaba y la confianza con el entrevistado (idealmente) se fortalecía (Harvey 2011; Mikecz 2012). Para iniciar la construcción de esta confianza, desde el primer contacto por teléfono y antes de cada entrevista, se le garantizó a el/la entrevistado/a el anonimato de su identidad personal en los reportes de la investigación resultantes. Por esta razón las citas de entrevistas que se presentan a continuación serán identificadas únicamente por el género del entrevistado, el partido al que pertenece (PRI, PAN, PRD) y la región en donde colaboraba al momento de la entrevista (ZMVM, Centro-O.). Se comenzará con una descripción breve de las religiosidades en los entornos familiares de los que son, o fueron, parte los entrevistados; y se continuará con una

6 A excepción de un entrevistado que después de la entrevista comentó haber renunciado a su partido unas semanas antes, los entrevistados de la región Centro-O. tenían cargos de dirigencia a nivel local o estatal (secretarios o presidentes municipales y estatales; coordinadores municipales y estatales); la mayoría de los entrevistados de la ZMVM tenían cargos de dirigencia a nivel nacional (secretarios o presidentes y coordinadores); algunos de éstos tenían cargos locales o estatales. Los cargos de dirigencia de la mayoría de los entrevistados se ubicaban en las sub-organizaciones de cada partido político dedicadas a sus miembros jóvenes: "Acción Juvenil" (PAN), "Juventudes de Izquierda" (PRD) y "Red Jóvenes por México” (PRI). 
descripción, también concisa, de las rupturas de los entrevistados con esas dimensiones religiosas del entorno, seguida por una descripción de las continuidades en/de los entrevistados con respecto a esas dimensiones y, antes de las conclusiones del texto, una descripción sucinta de la opinión de los entrevistados acerca de las religiosidades de otros políticos.

\section{Religiosidades en los entornos familiares}

Aunque en ocasiones las preguntas sobre las afiliaciones, prácticas y creencias religiosas (religiosidades, en suma) de los entrevistados y de su entorno familiar fueron contestadas con respuestas breves ${ }^{7} \mathrm{o}$ un tanto evasivas ${ }^{8}$, la evidencia apunta a que todos los entrevistados crecieron en familias en donde al menos uno de los padres está, o estaba, afiliado a religiones cristianas. La mayoría (30) de los entrevistados reportaron haber crecido en familias donde al menos uno de los padres es católico nominal $o$ practicante. Únicamente una entrevistada del PRI y uno del PRD, ambos en Centro-O., reportaron que sus padres no son católicos sino cristianos y cristianos evangélicos respectivamente. Con respecto a la intensidad o frecuencia de prácticas religiosas dentro de las familias de los entrevistados, la evidencia muestra una variación por regiones esperada hasta cierto punto. Es decir, en la región Centro-O., incluso los dirigentes de partidos de centro y de izquierda describieron un nivel de prácticas religiosas familiares considerable. Por ejemplo, el entrevistado (PRD, Centro-O.) que describió a sus padres como cristianos

7 Esta brevedad de respuestas resultó claramente opuesta a las respuestas extensas que ofrecieron cuando se les preguntaba sobre temas exclusivamente políticos.

8 Un entrevistado, por ejemplo, comentó con seriedad: "[...] yo pertenezco a una religión y aun así no estoy de acuerdo con todo lo que dice la religión a la que pertenezco $[\ldots]$... bueno voy a decirlo, soy católico, y toda mi vida he estado en ese tipo de escuelas y la verdad no estoy de acuerdo [...] en todo lo que dicen" (hombre, PRI, ZMVM). 
evangélicos, reportó que su padre es pastor evangélico de una iglesia. Otro entrevistado en esta región comentó sobre las "procesiones, eventos religiosos y demás" (hombre, PRI) a los que asiste junto con su familia ${ }^{9}$.

Por otro lado, la frecuencia/intensidad de las prácticas religiosas familiares en los entrevistados de la ZMVM fue menor. Por ejemplo, un entrevistado declaró que su familia es católica y que durante su infancia asistía a la iglesia "no cada ocho días, pero sí cada quince días" (hombre, PRD, ZMVM). Reflejando aún más desapego, una entrevistada comentó: "[c]recí con un papá agnóstico [...] que no disfrutaba [...] vernos en la Iglesia católica todo el tiempo" (Mujer, PRD, ZMVM).

En cuanto a la intensidad o grado de las creencias religiosas de las familias (nucleares y extendidas) de los entrevistados, las evidencias, aunque no son idénticas son un tanto más consistentes, tanto en las dos regiones como en los tres partidos; por ejemplo, un dirigente del Centro-O. declaró que su madre "súper adora [sic] a la Virgen de Guadalupe" (hombre, PAN). Una dirigente del PRI, en la misma región, mencionó de manera similar la manera en que su abuela demostraba creencia decidida en sacerdotes católicos. En la ZMVM una entrevistada (PRI) comentó: "mi abuela, [...] ella sale el domingo de la iglesia y dice que lo que el padrecito dijo es ley" (PRI). En la misma región, un entrevistado (PRD) comentó que cuando era pequeño jugaba junto con sus primos "a ser Cristo" y más tarde, en tono reflexivo, añadió que había crecido en una zona de la ZMVM en donde representaciones públicas y multitudinarias de la muerte

9 Vale la pena anotar que en algunos dirigentes del PAN (derecha) en Centro-O. se encontró evidencia un tanto contraria. Por ejemplo, un entrevistado reportó enfáticamente que en su familia no acostumbraban "ir todos los domingos a misa" ni "estar muy cercanos con la Iglesia católica” (Hombre, PAN, Centro-O.). 


\section{SIWÔ `' Volumen 9, Números 1, 2015}

y resurrección de Cristo, de acuerdo al dogma católico, son parte de las tradiciones locales.

\section{Rupturas con las religiosidades del entorno}

A pesar de las menciones medianamente comunes acerca de las prácticas y, sobre todo, acerca de las creencias religiosas de las familias de los entrevistados, éstos tienen una clara idea de sus rupturas con las instituciones eclesiales y algunas de sus normas comportamentales y valores morales. Este alejamiento es evidente en entrevistados de las dos regiones y, hasta cierto grado, de los tres partidos; por ejemplo, una de las entrevistadas declaró ser "creyente" mas no católica, porque "ser católica sería [...] [hacer] todo lo que la Iglesia católica te dice que tienes que hacer" (PRI, Centro-O). Un entrevistado brevemente comentó "yo soy católico, pero no soy de iglesia" (PAN, Centro-O). En la ZMVM, un entrevistado críticamente declaró: "la institución eclesial [...] ha sido un gran freno para el desarrollo de nuestro país" (Hombre, PRD). Un entrevistado del PAN comentó sobre la necesidad de distinguir "los fines de la Iglesia" de aquellos "del clero" y después añadió "puede haber objetivos muy terrenales para el clero, que tienen que ver [...] con propiedades, con políticas públicas [favoritistas], pero los fines de la Iglesia no necesariamente están representados por los [...] del clero" (ZMVM). Otro entrevistado refirió la forma en que para él "es molesto" asistir a misas católicas porque, entre otras cosas, "el padre [sacerdote] se la pasa lacerando a la mujer diciendo 'es que tú tienes que cargar con esto [como esposa fiel]"” (PRD, ZMVM).

Las rupturas de los entrevistados con las religiosidades del entorno no se relacionan únicamente con elementos eclesiales institucionales. A excepción de varios dirigentes del PAN-ZMVM y de un par de entrevistados de otros partidos, la mayoría de los 
entrevistados en las dos regiones y en los tres partidos, mantienen distancia y escepticismo hacia ciertos "valores religiosos"10 o hacia cierto tipo de aplicación de los mismos. Por ejemplo, un entrevistado del partido de derecha expresó su escepticismo sobre valores católicos como el rechazo al matrimonio homosexual y al aborto, en su opinión este escepticismo se da porque los jóvenes actualmente tienen "una visión más científica de las cosas" (PAN, Centro-O.).

De forma similar algunas de las entrevistadas criticaron los estereotipos de género y sexualidad conservadora que se refuerzan en discursos religiosos; por ejemplo, una de ellas expresó su desacuerdo sobre la idea de que "la mujer es [...] para estar hecha en casa y para el cuidado de los hijos" (PAN, ZMVM); otra entrevistada expresó la necesidad urgente para las mujeres de "tener una formación sexual adecuada" que deje atrás la "ignorancia [que] se tenía antes por miedo a [la] religión” (PRI, ZMVM $)^{11}$. Con mucho menor escepticismo, una entrevistada comentó que los valores religiosos "no son los que están mal", sino los "fanatismos", es decir, "la interpretación [fundamentalista]” (PAN, ZMVM), que se les daría a esos valores.

10 Durante las entrevistas se prefirió no definir el concepto de valor religioso para incrementar la variedad de respuestas y evitar un sesgo apriorístico; se daba al entrevistado libertad de interpretar el término "valor religioso" de acuerdo a su propio criterio. En algunas entrevistas los entrevistados insistieron en que se les diera un ejemplo de valor religioso, en cuyo caso fue mencionado el concepto de Los Diez Mandamientos de acuerdo al catecismo católico.

11 La mayoría de los entrevistados, incluida una minoría del partido de derecha, expresaron durante la entrevista su apoyo en lo general hacia políticas de aborto asistido y matrimonios homosexuales (ver De la Torre y Gutiérrez 2008: 401-3). 


\section{Continuidades en términos de creencias y valores religiosos}

La mayoría de los hombres dirigentes entrevistados del PAN en la ZMVM mostraron posiciones considerablemente más conservadoras en relación a sus desacuerdos con valores religiosos. Por ejemplo, después de la pregunta expresa sobre los valores religiosos con los que no estaban de acuerdo, dos dirigentes declararon estar "de acuerdo en todo" lo relacionado a valores católicos (hombres, PAN, ZMVM). Una posición similar fue reportada por un entrevistado del PRD en la ZMVM quien afirmó que es necesario mantener la "ética católica" en el "fuero privado", pero declaró estar de acuerdo "en todos" los valores católicos.

A excepción de los casos anteriores, la evidencia indica que las continuidades entre las religiosidades del entorno y las creencias y valores religiosos de los entrevistados son parciales, pero ciertamente presentes. Solo uno de los entrevistados reportó que "no estaría de acuerdo en casi todo" lo relacionado con valores religiosos (hombre, PRD, Centro-O.). Por el contrario, otro entrevistado en Centro-O. declaró ser católico tanto "por herencia" como "por convicción" y después dijo estar de acuerdo con los "valores familiares" de la Iglesia católica (hombre, PRI). En esta misma región, otro entrevistado comentó que "hay cuestiones [sobre valores religiosos] muy importantes, como ayudar al prójimo, no robar, no matar", y después añadió "también soy creyente [...] de las familias monogámicas” (Hombre, PRD).

En la ZMVM un dirigente comentó haber cursado todos sus estudios en escuelas católicas y más tarde declaró que, aunque es escéptico en lo general, sí hay valores religiosos que el comparte como "el trato con las personas, el aceptar a las personas" (hombre, PRI). Una entrevistada del mismo partido se expresó al respecto como sigue: "con los [valores religiosos] que me quedo 
es [...] ayudar al prójimo, pensar siempre en el prójimo incluso antes que en ti (Mujer, PRI, ZMVM). En otro partido, un entrevistado declaró que él no hace "lo que la Iglesia [...] dice", pero trata "de hacer bien con el prójimo" de la manera en que él cree "que es la correcta" (PRD, ZMVM).

En cuanto a la creencia en Dios o un dios, las evidencias son consistentes en los tres partidos y dos regiones. A excepción de un entrevistado que se declaró "agnóstico" y declaro que no podía "probar ni negar la existencia de Dios" (hombre, PRD, ZMVM), el resto de los entrevistados reportaron mantener una creencia en Dios o un dios con mayor o menor escepticismo. Por ejemplo, un entrevistado en Centro-O. se expresó al respecto de la siguiente forma: "[c]reo en algo más allá de... [...] Sí, se puede llamar Dios. [...]. Podría ser un arquitecto como le denominan los masones, podría ser un Yahvé, podría ser un Alá" (Hombre, PRI).

En la misma región, otro entrevistado declaró su escepticismo acerca de la naturaleza antropomorfa que el dogma religioso (católico) le ha asignado a la figura de Dios, pero en lo general expresó creencia en el concepto (hombre, PRD). En la ZMVM, un entrevistado del partido de derecha expreso, con mucho menor escepticismo, que era "irracional" el "pensar que Dios no existe, $[\ldots]$ pensar que todo es causa de, [...] un error o de una coyuntura universal para que estemos platicando aquí tú y yo" (Hombre, PAN, ZMVM). Otro entrevistado en la ZMVM expresó que "es básico tener fe, es básico creer en un poder superior, en un dios [...], de hecho, yo diría que es algo esencial hacerlo" (Hombre, PRI). 


\section{SIWÔ ’ Volumen 9, Números 1, 2015}

\section{Lo religioso en los otros.}

Cuando uno de los entrevistados en la ZMVM abordó el tema de lo religioso en su partido, expresó lo siguiente: "[...] el 12 de diciembre, los perredistas, todos los diputados, diputados locales y federales, jefe de gobierno, o sea muchos, festejan [el día de la Virgen de Guadalupe] a manera como lo festeja el 92\% de la población, un festejo, [...] muy espiritual, de rezar, de cantarle las mañanitas a la Virgen, algo muy tradicional." (Hombre, PRD). Cuando se le pregunto en específico sobre la afiliación religiosa de otros jóvenes de su partido, comentó que el 90\% serian católicos, aunque católicos "de palabra". Cuando se le pregunto si esos compañeros creerían en la Virgen de Guadalupe contestó "sí [...] sí, la mayoría [...] el 80\% es guadalupano, o al menos [aunque no lo digan] sabemos que son guadalupanos" (hombre, PRD, ZMVM). Por otro lado, una dirigente del mismo partido expresó que un $60 \%$ de sus compañeros jóvenes de partido serian "ateos"; un 15 o 20\% "se dicen religiosos" y el 20\% restante pertenecerían al "cristianismo"12 (mujer, PRD, ZMVM).

En la región Centro-O., un entrevistado también del PRD expresó que la mayoría de sus compañeros de partido son católicos. Otro entrevistado declaró: "muchos [...] hasta son fanáticos de la virgen o de algún santo porque [...] es parte de la cultura mexicana" (PRD, Centro-O.). Por el contrario, una entrevistada del mismo partido enfatizó la diferencia en afiliación y creencias religiosas entre los jóvenes de su partido y los del partido de derecha. Desde su perspectiva, en el PAN el ser católico es un "requisito" y después describió a dos dirigentes jóvenes panistas, con los que había discutido en un debate público, como "súper

12 Una encuesta relativamente reciente sobre valores de la población joven en México (Instituto Mexicano de la Juventud 2012) reporta que en la muestra analizada (N: 5000; $12-29$ años) el 79.1\% reportó creer en "la virgen de Guadalupe", el 74.1\% reportó creer en "los milagros", el 71.1\% en "el pecado", el 67.1\% en "santos" (Instituto... 2012:39). 
católicos, los dos iban a misa, los dos estaban en contra de todo lo que la Iglesia [católica] estuviera" (mujer, PRD, ZMVM).

Los entrevistados del PAN confirmaron hasta cierto punto este perfil religioso en sus compañeros de partido, aunque rechazaron la idea de la afiliación católica como requisito. Uno de ellos, por ejemplo, comentó que de los 200 jóvenes militantes que conoce en su jurisdicción el $80 \%$ son católicos y que la mitad "sí son practicantes" (hombre, PAN, Centro-O.).

Los porcentajes que los dirigentes del PAN asignaron a miembros jóvenes de otros partidos variaron un tanto, pero concluyeron en que al menos en el PRI el número de católicos es considerable. Por ejemplo, una dirigente del PAN comentó con ironía que en el PRI habría 80\% de católicos y 20\% "que dicen 'yo no creo en nada' pero van a misa" (mujer, PAN, ZMVM). Aunque en algunos entrevistados del PRI hubo resistencia a hablar sobre los perfiles religiosos de compañeros militantes, algunos de ellos compartieron sus estimaciones. Uno de ellos, en la región Centro-O., comentó que la mayoría de sus compañeros son católicos y que sólo un 5\% serian posiblemente ateos. En la ZMVM un entrevistado comentó en términos generales que en su partido "hay una gran cantidad de jóvenes que son adeptos a una religión" (hombre, PRI). Otro dirigente del mismo partido comentó que un 70\% de los miembros jóvenes del PRI serian católicos, un 25\% "sería variado" y un 5\% "a lo mucho, [...] seria gente atea" (hombre, PRI). Cabe señalar también que se encontró una diferencia notable entre la seguridad con la que los entrevistados describieron las religiosidades de otros jóvenes políticos y las evasiones y ambivalencias que los mismos individuos mostraron al momento de hablar de sus propias creencias y perfiles religiosos. Al respecto, un entrevistado comentó que los jóvenes miembros de partidos políticos "no exponen su espiritualidad 


\section{SIWÔ ’ Volumen 9, Números 1, 2015}

porque saben que [esa espiritualidad] es [objeto de] un rechazo natural [por parte] de los jóvenes" (hombre, PRI, ZMVM).

\section{Conclusiones.}

Desde un abordaje únicamente micro-analítico y sincrónico, las evidencias anteriores indican heterogeneidades relevantes en las creencias y valores religiosos de los entrevistados y su entorno, de acuerdo a la región en la que éstos se localizan y al partido al que están afiliados. Mientras que el grado de prácticas religiosas en los entornos familiares de los entrevistados de Centro-O., puede describirse como considerable, el grado del mismo factor en los entornos familiares de la ZMVM sería menor. Sin embargo, las divergencias esperadas por regiones no pueden generalizarse. Cabe anotar, por ejemplo, la diferencia entre los entrevistados del PAN en Centro-O., y en la ZMVM -comparados con los primeros, los entrevistados del PAN en la ZMVM, tanto hombres como mujeres, mostraron en su conjunto más apego a los valores, creencias y prácticas religiosas católicas.

$\mathrm{Al}$ respecto es preciso señalar las religiosidades relativamente más escépticas que mostraron los entrevistados afiliados al partido de izquierda (PRD) tanto en Centro-O., como en la ZMVM. No obstante estas diferencias específicas, las interpretaciones de las evidencias anteriores estarían incompletas sin un abordaje más comprensivo. En este sentido micro-meso, son relevantes las similitudes entre los grados de creencias religiosas en los entornos familiares de los entrevistados de las dos regiones. Aunque una atmósfera de escepticismo fue más palpable en los entrevistados del PRI (centro) y PRD (izquierda) en la ZMVM, no es casual que uno de los entrevistados del partido de izquierda en esta región reportara haber jugado en su infancia a representar la figura de Cristo y uno más de sus compañeros de partido 
declarara ser "católico convencido" y estar de acuerdo en todos los valores católicos.

No es tampoco casual que un entrevistado del partido de centro (PRI) en la ZMVM calificara como esencial el creer en un dios, y que una entrevistada del mismo partido declarara apegarse al valor católico de ayuda al prójimo, de forma casi idéntica a los dos entrevistados del PRD (Centro-O. y ZMVM), que se refirieron a ayudar o hacer bien al prójimo como un valor religioso que ellos sostienen. Aunque los valores religiosos (católicos) de género y sexualidad fueron criticados por la mayoría de los entrevistados, éstos últimos y sus valores morales y comportamentales no se muestran separados totalmente de los valores religiosos (católicos) de tipo cívico-ético (Stack 2012). Puede, por tanto, inferirse que los criterios de "auto-gobierno" (Bröckling, Krasmann, Lemke 2011:2) de los entrevistados están en mayor o menor grado alimentados por criterios religiosos cívico-éticos. Las posibles relaciones y los mecanismos de vinculación entre dichos criterios cívico-éticos, las lógicas de macro-gobierno de los entrevistados y metodologías de gobierno pastoralistas constituyen objetivos cruciales para futuros análisis.

\section{Referencias bibliográficas}

Agamben, Giorgio. The kingdom and the glory. For a Theological Genealogy of Economy and Government. Stanford: Stanford University Press, 2011. Impreso.

Bastian Jean-Pierre. "Los nuevos partidos políticos confesionales evangélicos y su relación con el Estado en América Latina". Estudios Sociologicos 17.49 (1999): 153-173. Impreso.

Blaikie, Norman. Designing social research. Cambridge: Polity Press, 2000. Impreso. 


\section{SIWÔ ${ }_{\text {volumen 9, Números } 1,2015}$}

Blancarte, Roberto. Historia de la iglesia católica en Mexico 1929. 1982. México DF: Fondo de Cultura Economica, 1992. Impreso.

Blancarte, Roberto, ed. Laicidad, religión y biopolítica en el mundo contemporáneo. México D.F.: El Colegio de Mexico, 2014. Impreso.

Bröckling, Ulrich, Krasmann, Susanne y Lemke, Thomas. Governmentality. Current Issues and Future Challenges. New York; London: Routledge, 2011. Impreso.

Bustamante, Fabián. "La participación de las Comunicaciones Eclesiales de Base en la regeneración de la sociedad civil durante las dictaduras militares". Revista Cultura y Religión, 3.1 (2009):160-171. Web. 5 Jun. 2015.

Casanova, Jose. Public religions in the modern world. Chicago: University of Chicago Press, 2001. Impreso.

Casanova, Jose. "Rethinking Secularization: A Global Comparative Perspective". The Hedgehog Review, número primavera-verano, (2006): 7-22. Web. 7 Jun. 2015.

Casanova, Jose. "The secular, secularisations, secularisms". Rethinking secularism. Calhoun Craig, Juergensmeyer Mark y VanAntwerpen Jonathan. Nueva York: Oxford University Press, 2011. 54-74. Impreso.

Contreras, Delia. "Iglesia católica y estado en la república de Cuba: pasado y presente de sus relaciones", América Latina Hoy, 63 (2012): 177-195. Web. 5 Jun. 2015.

De la Torre, Renee y Gutierrez, Cristina. "Tendencias a la pluralidad y la diversificación del paisaje religioso en el México contemporáneo", Sociedade e Estado, Brasília 23.2 (2008): 381-424. Web. 2 Jun. 2015.

Duque, Javier. "Las comunidades religiosas protestantes y su tránsito hacia lo político-electoral en Colombia, 1990-2007". 
Revista Mexicana de Sociologia, 72.1 (2010):73-111. Web. 7 Jun. 2015.

Federación Nacional de Municipios de México. Geografia Política Muncipal, Web. 4 Jun. 2015.

http://www.fenamm.org.mx/site/index.php?option=com_conte nt\&view $=$ article\& $i d=187 \&$ Itemid $=111$

Fediakova Evguenia, Parker Cristián. "Evangelicos chilenos: ¿apolíticos o nuevos ciudadanos?", Sí somos americanos. Revista de estudios transfronterizos 8.1 (2006): 127-141. Web. 7 Jun, 2015.

Foucault, Michel. "Nietzsche, genealogy, history". Language, counter-memory, practice: selected . essays and interviews. Bouchard, Donald, ed. Ithaca: Cornell University Press, 1977. 139-164. Impreso.

Foucault Michel. "The subject and power". Michel Foucault: beyond structuralism and hermeneutics. Dreyfus, Hubert y Rabinow, Paul, eds. Chicago: The University of Chicago Press, 1983. 208-226. Impreso.

Foucault, Michel. The birth of the clinic. London: Routledge Classics, 2003. Impreso.

Foucault, Michel. Security, territory, population, lectures at the College de France 1977-78. Basingstoke: Palgrave Macmillan, 2007. Impreso.

Foucault, Michel. "Omnes et Singulatim: Towards a Criticism of 'Political Reason"'. The Tanner Lectures on Human Values, v. 2. McMurrin Sterling, ed. Salt Lake City; Cambridge: University of Utah, Cambridge University Press, 2011. Impreso.

Foucault, Michel. On the government of the living. Basingstoke: Palgrave Macmillan, 2014. Impreso.

Freston Paul "«Neo-Pentecostalism» in Brazil: Problems of Definition and the Struggle for Hegemony", Archives de 


\section{SIWÔ ’ volumen 9, Números 1, 2015}

sciences sociales des religions, 105 (1999): 145-162. Web. 4 Jul. 2015.

Freston, Paul, ed. Evangelical Christianity and Democracy in Latin America, New York: Oxford, 2008. Impreso.

Freston, Paul. "Las dos transiciones futuras: católicos, protestantes y sociedad en América Latina”. Religión, política y cultura en América Latina. Nuevas Miradas. Parker, Cristian, ed. Santiago de Chile: Instituto de Estudios Avanzados, Universidad de Santiago de Chile, 2012. 77-97. Impreso.

Franco, Ivan. El PRI y sus obispos: el caso Berlié, Buenos Aires: Libros de la Araucaria, 2009. Impreso.

Harvey, William. "Strategies for conducting elite interviews". Qualitative Research, 11.4 (2011): 431-441. Web. 7 Jun, 2015.

Instituto Mexicano de la Juventud. Encuesta Nacional de Valores en Juventud 2012, México: Instituto Mexicano de la Juventud, Universidad Nacional Autónoma de México, Instituto de Investigaciones Juridicas, 2012. Web. 1 Jun. 2015. http://www.juridicas.unam.mx/invest/areas/opinion/envaj/pdf/resumen.pdf

Lamas, Marta. "El aborto en la agenda del desarrollo en América Latina", Perfiles Latinoamericanos, 31 (2008): 65-93. Web 4 Jul. 2015.

Lefort, Claude. "The Permanence of the Theologico-political?". Political theologies. De Vries Hent y Sullivan Lawrence. Nueva York: Fordham University Press, 2006. 148-187. Impreso.

Löwy, Michael. The war of gods. Religion and politics in Latin America. London; New York: Verso, 1996. Impreso.

Mancilla, Alma. "Las representaciones de la religión en el espacio público entre los líderes religiosos minoritarios en México", Revista de Estudios Sociales, 39 (2011): 80-94. Web. 22 May. 2015. 
Maroto, Adriana. "Intercambio de obsequios y contraobsequios: construcción de la legitimidad en las relaciones estadoiglesia católica en Costa Rica, 2007-2010”, Anuario de Estudios Centroamericanos, 40 (2014): 289-310. Web. 16 Jul. 2015.

Marroquin, Enrique. "Lo religioso en el conflicto de Chiapas". Espiral. Estudios sobre Estado y Sociedad, 3.7 (1996): 143158. Web. 5 Jul, 2015.

Masferrer, Elio. Religión, política y metodologías. Aportes al estudio de los sistemas religiosos. Buenos Aires: Libros de la Araucaria, 2013. Impreso.

Mason, Jennifer. Qualitative researching. London: Sage, 2002. Impreso.

Mikecz, Robert. "Interviewing Elites: Addressing Methodological Issues". Qualitative Inquiry 18.6 (2012): 482-493. Web. 20 May. 2015.

Morán, Jose Manuel. "Feminismo, Iglesia Católica y derechos sexuales y reproductivos en el Chile post-dictatorial", Estudos Feministas, Florianópolis, 21.2 (2013): 485-508. Web. 5 Jul. 2015.

Parker, Cristián. "Introducción. Religión, cultura y política en América Latina: nuevos enfoques", Parker, Cristian, ed. Religión, política y cultura en América Latina: nuevas miradas. Santiago de Chile: Instituto de Estudios Avanzados, Universidad de Santiago de Chile, 2012. 13-73. Web. 2 Nov. 2014.

Pew Research Center. The future of world religions. Population growth projections 2010-2050, (sin lugar de edición), 2015. Impreso.

Prieto, Sol. "El desempeño de los partidos confesionales católicos en Argentina: una revisión crítica”. Religião $\mathcal{E}$ Sociedade, 34.2 (2014): 114-138. Web. 5 Jul. 2015. 


\section{SIWÔ ${ }_{\text {volumen 9, Números } 1,2015}$}

Reed, Jean-Pierre. "Religious Dialogue in the Nicaraguan Revolution", Religion and Politics, 1 (2008): 277-299. Web. 6 Jul. 2015

Restrepo, Nicolás. "La iglesia católica y el estado colombiano, construcción conjunta de una nacionalidad en el sur del país", Tabula Rasa, 5 (2006): 151-165. Web. 8 Jul. 2015.

Ruibal, Alba (2014) Movement and counter-movement: a history of abortion law reform and the backlash in Colombia 2006-2014, Reproductive Health Matters, 22(44): 42-51. DOI: $10.1016 /$ S0968-8080(14)44803-1.

Schmitt, Carl. Political theology. Four chapters on the concept of sovereignity. Chicago; Londres: The University of Chicago Press, 1985. Impreso.

Seidman, Irving. Interviewing as qualitative research. New York; London: Teachers College Press, 2006. Impreso.

Stack, Trevor. "Scholasticism, Liberalism, Revolutionary Nationalism and Neoliberalism in Mexico". Liberalism and Religion: Secularisation and the Public Sphere in the Americas. Londres: Senate House, London. Web. 10 Ago. 2013. Http://sas-space.sas.ac.uk/id/eprint/4171.

Steigenga, Timothy. The politics of the spirit: the political implications of Pentecostalized religion in Costa Rica and Guatamala. Lanham: Lexington Books, 2001. Impreso.

Strassner, Veit. "La Iglesia chilena desde 1973 a 1993: De buenos samaritanos, antiguos contrahentes y nuevos aliados. Un análisis politológico", Teología y Vida, 67 (2006): 76-94. Web. 5 Jul. 2015.

Vazquez, Felipe. "Democratic activity and religious practices of evangelicals in Mexico". Evangelical Christianity and Democracy in Latin America. Freston, Paul, ed. New York: Oxford University Press, 2008. 37-61. Impreso. 
Vieira, Jessie. "Acomodações recíprocas: a igreja católica e o poder temporal na Argentina e no Brasil", Passagens. Revista Internacional de História Política e Cultura Jurídica, 1.2 (2009): 50-64. DOI: 10.5533/1984-2503-20091204.

Zavala-Pelayo, Edgar. "Pastoral power outside Foucault's Europe: public education and the 'epistemic authority' of social scientists in Mexico", Journal of Political Power, 7.1 (2014): 87-106. Impreso.

Zavala-Pelayo, Edgar. "Another pastoral power: spiritual salvation through worldly integralism in colonial Latin America", documento de trabajo, Center for Area Studies, Freie Universität Berlin, 2016.

Zub, Roberto. "The evolution of protestant participation in Nicaraguan politics and the rise of evangelical parties". Evangelical Christianity and Democracy in Latin America. Freston, Paul, ed. New York: Oxford University Press, 2008. 97-129. Impreso. 